http://jmscr.igmpublication.org/home/ ISSN (e)-2347-176x ISSN (p) 2455-0450 crossref DOI: https://dx.doi.org/10.18535/jmscr/v8i8.16

\title{
A Comparative Study of Efficacy of Magnesium Sulphate and Nifedipine in Pre- Term Labour
}

\author{
Authors \\ Dr Shaesta Iqbal ${ }^{1}$, Dr Sipra Singh ${ }^{2}$, Dr Shabnam Phuleman ${ }^{3}$ \\ ${ }^{1,3} \mathrm{PGT} 3^{\text {rd }}$ year Department of obstetrics \& Gynaecology, KMCH \\ ${ }^{2}$ Professor, Department of Obstetrics \& Gynaecology, KMCH
}

\begin{abstract}
Background: The present study was conducted to compare the Efficacy of MgSO4 and Nifedipine in PreTerm Labour.

Materials \& Methods: The present study was conducted on 70 patients in active preterm labor who were 24 weeks to 33 weeks and 6 days gestation. Patients were divided into 2 groups. Group I patients received Magnesium Sulfate and group II patients received Nifedipine. In Both Groups, Primary outcome and Secondary outcome was recorded. Adverse effects were also recorded.

Results: There were no differences between the groups in the proportion of patients who delivered within 48 hours, Gestational age at delivery and delivery before 37 weeks $(P<0.05)$. The mean birth weight of babies in group I was 2510 grams and in group II was 2630 grams, Respiratory Distress Syndrome (RDS) was seen in 8 in group I and 7 in group II, Intraventricular Hemorrhage (IVH) was seen in 1 in group I only and Necrotizing Enterocolitis (NEC) was not seen in any group, sepsis was seen in 2 in Group I and 1 in Group II, death 1 in group I only. Neonatal Intensive Care Unit admission (NICU) was seen in 18 in group I and 13 in group II and mean days in NICU was 8.2 days in Group I and 4.1 days in Group II.

Conclusion: Authors found that more patients in Group I achieved the Primary outcome of prevention of Preterm delivery for 48 hours with uterine quiescence as compared to Group II. Nifedipine was associated with fewer maternal adverse effects as compared to Magnesium Sulphate.

Keywords: Magnesium sulphate, Nifedipine, Pre term labour.
\end{abstract}

\section{Introduction}

The incidence of Preterm birth is $9 \%-13 \%$ of births. Between 1989 and 2000 spontaneous Preterm birth and Premature birth due to Premature Rupture of Membrane (PROM) declined $0.4 \%$ among singletons. ${ }^{1}$ The increasing rate of Preterm birth has resulted in part from an increase in preterm delivery for medical indications and an increase in multiple gestations. Neonatal outcomes have improved at all gestational ages due in part to antenatal steroid administration, tocolytic agents use and improvements in neonatal care. $^{2}$

Tocolytic agents such as Beta Mimetics, Calcium Channel Blockers, Oxytocin Receptor Antagonists, and Magnesium Sulfate (MgSO4) are used to suppress preterm labor. The first-line Tocolytic drug in North America is $\mathrm{MgSO} 4 .^{3}$ But in European countries, $\mathrm{MgSO} 4$ is seldom used for tocolysis. Crowther et $\mathrm{al}^{4}$ in their study declared that $\mathrm{MgSO} 4$ administration did not result in a statistical reduction in birth $<48$ hours. In 
addition, $\mathrm{MgSO} 4$ may be associated with an increase in maternal and neonatal adverse effect.

Nifedipine may be more easily tolerated, is administered orally, and appears to have few adverse effects, although severe dyspnea, hypoxia, and myocardial infarction have been reported among pregnant women. ${ }^{5}$ When compared with Betamimetics, Nifedipine has been associated with fewer adverse reactions, prolonged gestation, and better neonatal outcomes. Nifedipine has been compared with Magnesium Sulfate in previous studies. ${ }^{6,7}$ The present study was conducted to compare $\mathrm{MgSO} 4$ and Nifedipine in pre- term labour.

\section{Materials \& Methods}

Study Design: It is a hospital based randomized prospective study

Study Place: Department of Obstetrics and Gynaecology Katihar Medical College and Hospital, Katihar, Bihar.

Study Peroid: August 2018 to August 2019 with a minimum period of 6 months follow up

Study Population: Sample Size of 70 pregnant patients attending Emergency of Obstertrics and Gynecology Department of Katihar Medical College and Hospital, Katihar were selected.

The present study was conducted among 70 patients in active preterm labor who were 24 weeks to 33 weeks and 6 days gestation. Ethical approval was obtained from institute prior to the study. All patients were informed regarding the study and written consent was obtained.

General information such as name, age etc. was recorded. Patients were divided into 2 groups. Group I received Magnesium Sulfate and Group II patients received Nifedipine. In Group I, patients received a 4 -g bolus followed by $2 \mathrm{~g} / \mathrm{h}$ infusion. In group II, patients received Nifedipine $10 \mathrm{mg}$ sublingually every 20 minutes for three doses total, followed by $20 \mathrm{mg}$ orally every 4 or 6 hours. The primary study outcome was prevention of delivery for 48 hours with attainment of uterine quiescence, defined by 12 hours of six or fewer contractions per hour and no further cervical change within 48 hours of tocolytic initiation. Failure of the Primary outcome occurred if in the first 48 hours-patients delivered, ruptured previously intact membranes, experienced recurrent preterm labor, continued to contract or change their cervix throughout, or required the use of supplemental or alternate tocolytics. Secondary outcomes included hours to quiescence, birth weight, gestational age at delivery, maternal adverse effects and neonatal morbidities, and length of stay. A composite of serious maternal adverse effects such as chest pain, pulmonary edema, shortness of breath, and hypotension were recorded. Neonatal outcomes were recorded. Results thus obtained were subjected to statistical analysis. P value less than 0.05 was considered significant.

\section{Results}

Table I Comparison of Parameters

\begin{tabular}{|l|c|c|c|}
\hline Parameters & Group I (35) & Group II (35) & P value \\
\hline Primary outcome & 31 & 25 & 0.05 \\
\hline Time to quiescence (Hours) & 6.1 & 8.2 & 0.01 \\
\hline Delivery in 48 hours & 1 & 2 & 0.91 \\
\hline Gestational age at delivery & 35.4 & 36.1 & 0.82 \\
\hline Gestational age less than 37 weeks & 19 & 20 & 0.94 \\
\hline
\end{tabular}

Table I, graph I shows that 31 patients in group I and 25 patients in group II achieved the primary outcome of prevention of preterm delivery for 48 hours with uterine quiescence. Among all patients who achieved the primary outcome, time to uterine quiescence was faster with group I patients
(6.1 hours) as compared to group II (8.2 hours). There were no differences between the groups in the proportion of patients who delivered within 48 hours, gestational age at delivery and delivery before 37 weeks $(\mathrm{P}<0.05)$. 
Graph I Comparison of Parameters

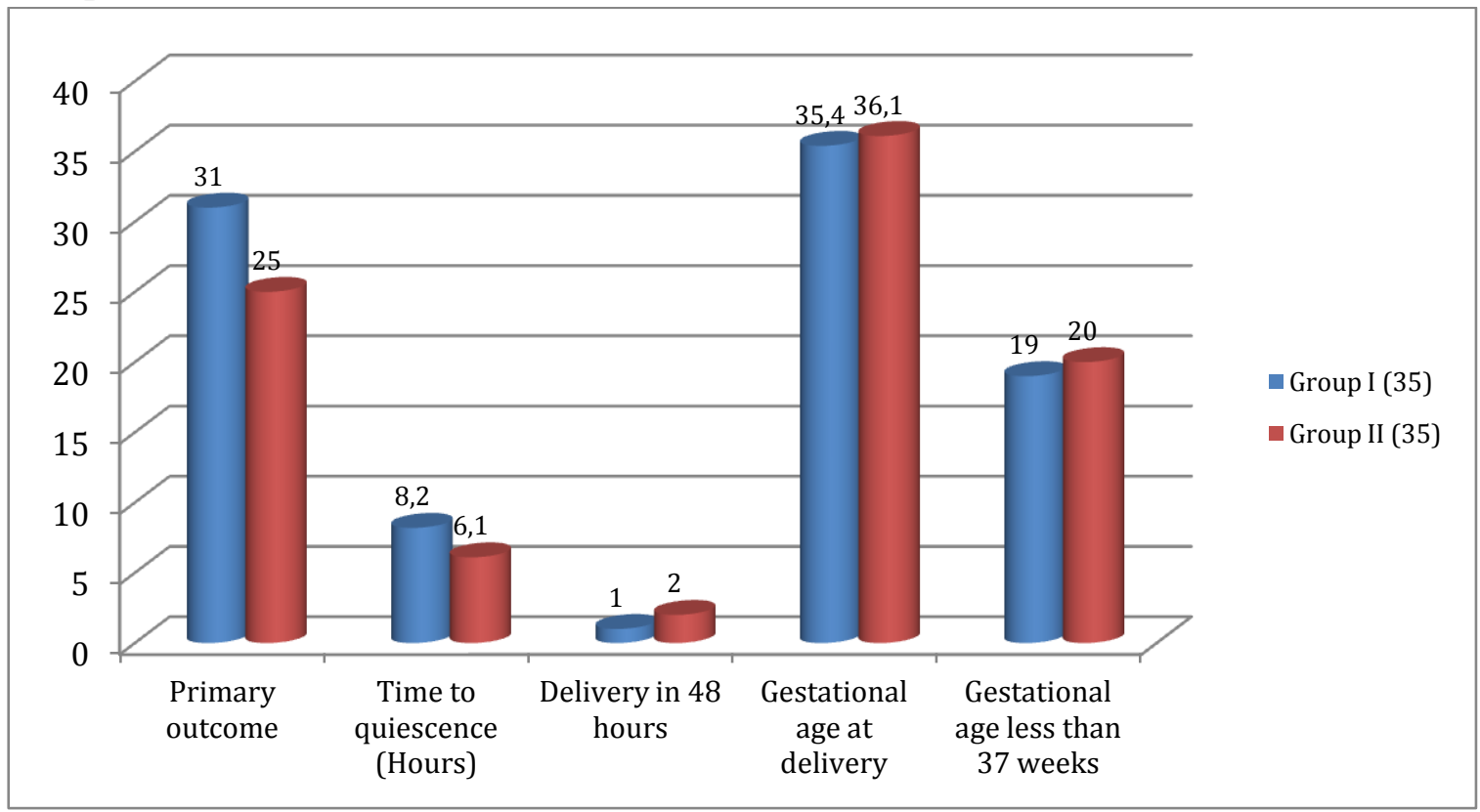

Table II Assessment of Neonatal Outcomes

\begin{tabular}{|l|c|c|c|}
\hline Variables & $\begin{array}{c}\text { Group I } \\
(\mathbf{3 5})\end{array}$ & $\begin{array}{c}\text { Group II } \\
(\mathbf{3 5})\end{array}$ & P value \\
\hline Birth weight (Grams) & 2510 & 2630 & 0.34 \\
\hline RDS & 8 & 7 & 0.91 \\
\hline NEC & 0 & 0 & 0 \\
\hline IVH & 1 & 0 & 0.90 \\
\hline Sepsis & 2 & 1 & 0.91 \\
\hline Death & 1 & 0 & 0.90 \\
\hline NICU admission & 18 & 13 & 0.02 \\
\hline Days in NICU & 8.2 & 4.1 & 0.001 \\
\hline
\end{tabular}

Table II shows that mean birth weight of babies in Group I was 2510 grams and in Group II was
2630 grams, Respiratory Distress Syndrome (RDS) was seen in 8 in Group I and 7 in Group II, Intraventricular Hemorrhage (IVH) was seen in 1 in Group I only and Necrotizing Enterocolitis (NEC) was not seen in any group, sepsis was seen in 2 in Group I and 1 in Group II, death 1 in Group I only. Neonatal Intensive Care Unit admission (NICU) was seen in 18 in Group I and 13 in Group II and mean days in NICU was 8.2 days in Group I and 4.1 days in Group II.

Graph II Adverse effects in both groups

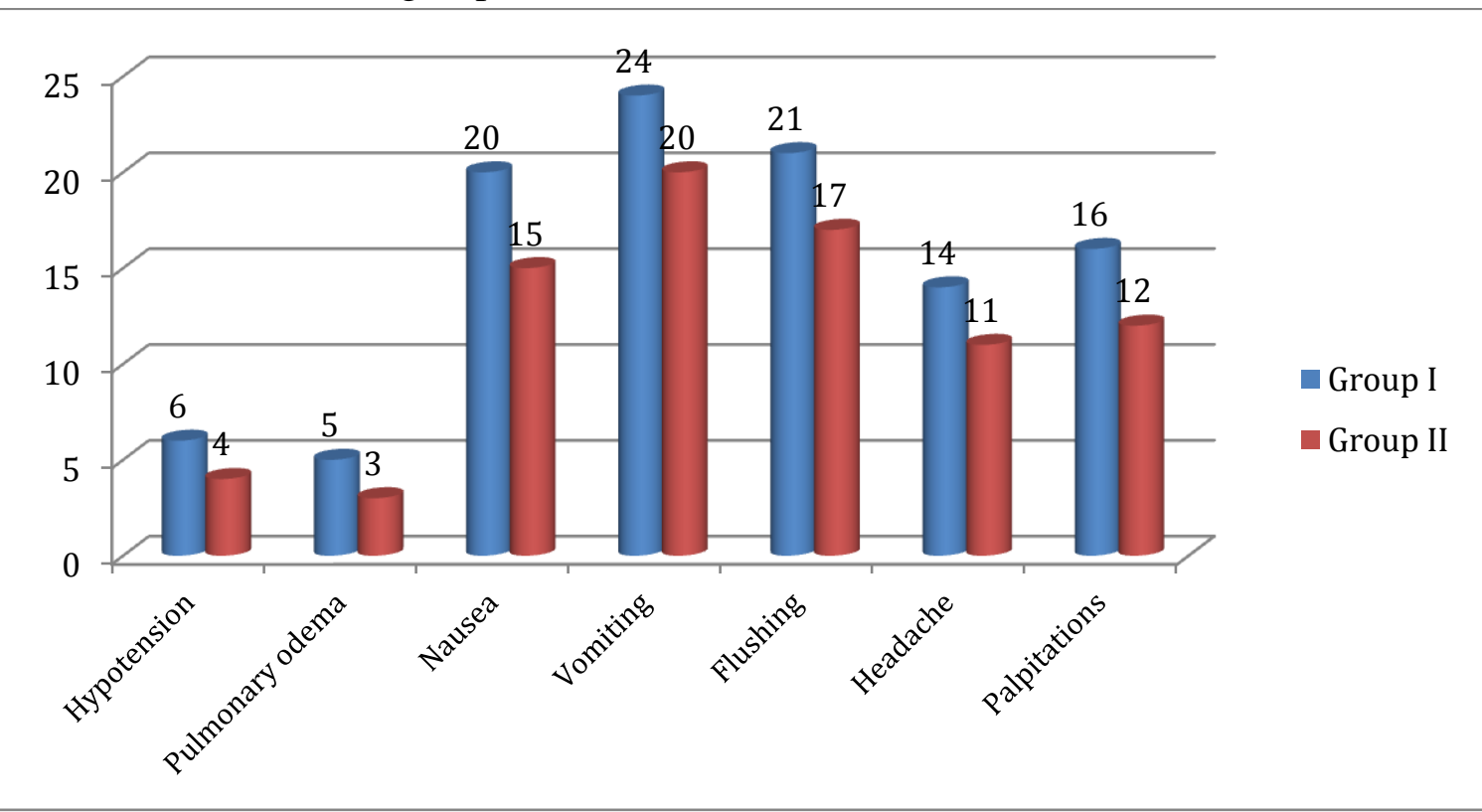


Graph II shows that adverse effects was hypotension was seen in 6 in Group I and 4 in Group II, Pulmonary Odema 5 in Group I and 3 in Group II, nausea 20 in Group I and 15 in Group II, vomiting 24 in Group I and 20 in Group II, flushing 21 in Group I and 17 in Group II, headache 14 in Group I and 11 in Group II, palpitations 16 in Group I and 12 in Group II.

\section{Discussion}

Preterm labour is one of the frequently encountered Emergencies in pregnancy. Premature labor can lead to an early birth. Preterm birth is a major cause of neonatal morbidity and mortality. More than $50 \%$ of preterm births are spontaneous. Preterm birth is defined as live babies born before 37 gestational weeks are completed which normally lasts for about 40 weeks. The present study was conducted to compare the efficacy of $\mathrm{MgSO} 4$ and Nifedipine in preterm labour.

In present study, group I patients received Magnesium Sulfate and group II patients received nifedipine. Each group had 35 patients. Khooshideh et $\mathrm{al}^{8}$ conducted a study on 220 women with preterm labor between 32 and 34 weeks of gestation. 110 received Nifedipine and 110 received $\mathrm{MgSO} 4$. There were not statistically significant differences in one-minute and five minute Apgar scores, neonatal Respiratory Distress syndrome between the two groups. Maternal hypotension was higher in the Nifedipine group, but the difference was not significant. Dyspnea and minor maternal side effects were significantly higher in the $\mathrm{MgSO} 4$ group than the Nifedipine group. Serious maternal adverse effects and severe hypotension were not seen in any of the groups.

We found that 31 patients in Group I and 25 patients in Group II achieved the primary outcome of prevention of preterm delivery for 48 hours with uterine quiescence. Among all patients who achieved the primary outcome, time to uterine quiescence was faster with Group I patients (6.1 hours) as compared to Group II (8.2 hours). There were no differences between the groups in the proportion of patients who delivered within 48 hours, gestational age at delivery and delivery before 37 weeks.

Lyell et al ${ }^{9}$ compared the efficacy and side effects of Intravenous Magnesium to oral Nifedipine for acute tocolysis of Preterm labor. Patients in active preterm labor who were at 24 to 33 weeks and 6 days of gestation were randomly assigned to receive Magnesium Sulfate or Nifedipine. The primary outcome was arrest of preterm labor, defined as prevention of delivery for 48 hours with uterine quiescence. One hundred ninety-two patients were enrolled. More patients assigned to Magnesium Sulfate achieved the primary outcome ( $87 \%$ compared with $72 \%, \mathrm{P}=.01$ ). There were no differences in delivery within 48 hours $(7.6 \%$ magnesium sulfate compared with $8.0 \%$ nifedipine), gestational age at delivery (35.8 compared with 36.0 weeks), birth before 37 and 32 weeks and episodes of recurrent preterm labor. Mild and severe maternal adverse effects were significantly more frequent with magnesium sulfate. Birth weight, birth weight less than 2,500 $\mathrm{g}$, and neonatal morbidities were similar between groups, but newborns in the magnesium sulfate group spent longer in the neonatal intensive care unit (8.8+/-17.7 compared with 4.2+/-8.2 days).

In our study, mean birth weight of babies in Group I was 2510 grams and in Group II was 2630 grams, Respiratory Distress Syndrome (RDS) was seen in 8 in Group I and 7 in Group II, Intraventricular Hemorrhage (IVH) was seen in 1 in Group I only and Necrotizing Enterocolitis (NEC) was not seen in any group, Sepsis was seen in 2 in Group I and 1 in Group II, death 1 in Group I only. We observed that neonatal Intensive Care Unit admission (NICU) was seen in 18 in Group I and 13 in Group II and mean days in NICU was 8.2 days in Group I and 4.1 days in Group II.

Nifedipine antagonizes voltage-dependent L-type calcium channels, causing vascular and smooth muscle relaxation, vasodilatation, reflexive cardioacceleration, and increased sympathetic 
tone. ${ }^{10} \mathrm{We}$ found that adverse effects was hypotension was seen in 6 in Group I and 4 in Group II, Pulmonary Odema 5 in Group I and 3 in Group III, nausea 20 in Group I and 15 in Group II, vomiting 24 in Group I and 20 in Group II, flushing 21 in Group I and 17 in Group II, headache 14 in Group I and 11 in Group II, palpitations 16 in Group I and 12 in Group II.

When used during hypertensive crisis, Nifedipine can lead to acute severe hypotension resulting in cerebrovascular ischemia, stroke, myocardial infarction, fetal distress, conduction disturbances, and death. ${ }^{11}$ The immediate release formulation can decrease blood pressure within 5 to 10 minutes. When used for tocolysis, diastolic blood pressure has been reported to decrease by $8 \%$ after the first sublingual dose, heart rate also increases, and the effect lasts for 3 hours. ${ }^{12}$

\section{Conclusion}

Authors found that more patients in Group I achieved the primary outcome of prevention of preterm delivery for 48 hours with uterine quiescence as compared to group II. Nifedipine was associated with fewer maternal adverse effects as compared to Magnesium Sulphate.

\section{References}

1. Ananth CV, Joseph KS, Oyelese Y, Demissie K, Vintzileos AM. Trends in preterm birth and perinatal mortality among singletons: United States, 1989 through 2000. Obstet Gynecol 2005;105: 1084-91.

2. Behrman RE, Butler AS, editors. Preterm birth: causes, consequences, and prevention. Washington (DC): National Academies Press; 2007; 398.

3. Norwitz ER, Robinson JN, Challis JR. The control of labor. $N$ Engl $J$ Med 1999;341:660-6. 5. Lewis DF. Magnesium sulfate: the first-line tocolytic. Obstet Gynecol Clin North Am 2005;32:485-500.
4. Crowther CA, Brown J, McKinlay CJ, Middleton P. Magnesium sulphate for preventing preterm birth in threatened preterm labour. Cochrane Database Syst Rev. 2014(8):CD001060.

5. Grimes DA, Nanda K. Magnesium sulfate tocolysis: time to quit. Obstet Gynecol 2006;108:986-9.

6. Glock JL, Morales WJ. Efficacy and safety of nifedipine versus magnesium sulfate in the management of preterm labor: A randomized study. Am J Obstet Gynecol 1993;169:960-4.

7. Haghighi L. Prevention of preterm delivery: nifedipine or magnesium sulfate. Int J Gynaecol Obstet 1999;66:297-8.

8. Khooshideh M, Rahmati J, Teimoori B. Nifedipine versus magnesium sulfate for treatment of preterm labor: Comparison of efficacy and adverse effects in a randomized controlled trial. Shiraz EMedical Journal. 2017 Jun;18(6).

9. Lyell DJ, Pullen K, Campbell L, Ching S, Druzin ML, Chitkara U, Burrs D, Caughey AB, El-Sayed YY. Magnesium sulfate compared with nifedipine for acute tocolysis of preterm labor: a randomized controlled trial. Obstetrics \& Gynecology. 2007 Jul 1;110(1):61-7.

10. Herschel M, Mittendorf R. Tocolytic magnesium sulfate toxicity and unexpected neonatal death. J Perinatol 2001; 21: 261-2.

11. Malaeb SN, Rassi AI, Haddad MC, Seoud MA, Yunis A. Bone mineralization in newborns whose mothers received magnesium sulphate for tocolysis of premature labour. Pediatr Radiol 2004;34:384-6.

12. Berkman ND, Thorp JM Jr, Lohr KN, Carey TS, Hartmann KE, Gavin NI, et al. Tocolytic treatment for the management of preterm labor: A review of the evidence. Am J Obstet Gynecol 2003;188:1648-59. 